\title{
METODE GEOLISTRIK RESTIVITAS \\ KONFIGURASI WENNER-SCHLUMBERGER DAN KONFIGURASI DIPOLE-DIPOLE UNTUK IDENTIFIKASI PATAHAN MANADO DI KECAMATAN PAALDUA KOTA MANADO
}

\author{
Jefriyanto Utiya ${ }^{1)}$, As'ari' ${ }^{1)}$, Seni HJ Tongkukut ${ }^{1)}$ \\ ${ }^{1)}$ Program Studi Fisika FMIPA UNSRAT MANADO \\ e-mail: jefriyanto.utiya@gmail.com; as.ari2222@yahoo.co.id; linashafii@yahoo.com
}

\begin{abstract}
ABSTRAK
Telah dilakukan penelitian untuk mendeteksi keberadaan Patahan Manado di Jalan Ringroad, Kelurahan Malendeng, Kecamatan Paaldua, Kota Manado, menggunakan metode geolistrik tahanan jenis konfigurasi Wenner-Schlumberger dan konfigurasi Dipole-dipole. Akuisisi data menggunakan multichannel and multielectrode resistivity and IP meter 46 simultaneous channel merek MAE X612-EM. Pengukuran dilakukan pada 4 lintasan dengan panjang masing-masing lintasan 480 meter. Pengolahan data dilakukan dengan menggunakan perangkat lunak RES2DINV dengan hasil berupa citra resistivitas bawah permukaan 2D. Diperoleh hasil bahwa bidang-bidang lemah pada lintasan 2 dan lintasan 4 dengan nilai resitivitas batuan berkisar $(2,72-86) \Omega m$, memotong perlapisan antara batuan yang memiliki resistivitas yang lebih tinggi. Bidang lemah tersebut diperkirakan sebagai rekahan yang ditemukan pada kedalaman $(2,50-40)$ meter dari permukaan tanah.
\end{abstract}

Kata Kunci : Wenner-Schlumberger, Dipole-dipole, RES2DINV, Patahan Manado.

\section{GEOELECTRIC RESISTIVITY METHOD WITH WENNER-SCHLUMBERGER AND DIPOLE-DIPOLE CONFIGURATIONS FOR IDENTIFICATION MANADO FAULT IN MANADO AT PAALDUA DISTRICTS}

\begin{abstract}
The research about detecting the presence of Manado Fault in Manado, Malendeng Village, Paaldua District, by using resistivity geoelectric method with Wenner-Schlumberger and Dipoledipole configurations, has been done. Multichannel and multielectrode resistivity and IP meters 46 simultaneous channels MAE brand X612-EM is device for acquisition of data. The Measurements were taken on four tracks with each length of track is 480 meters. The data processing was performed with RES2DINV software that results 2D image subsurface resistivity. The results indicate that the weak areas on the track 2 and track 4 with range value of rock resitivitas is $2.72 \Omega m$ to till $86 \Omega m$, cut the bedding between rocks which have higher resistivity. The weak areas is estimated as the fracture on the depth (2.50 to 40) meters from the ground.
\end{abstract}

Keywords: Wenner-Schlumberger, Dipole-dipole, RES2DINV, Fault Manado.

\section{PENDAHULUAN}

Sulawesi Utara merupakan salah satu daerah yang rawan bencana gempabumi karena geologis Sulawesi Utara terletak pada daerah pertemuan lempeng besar yaitu lempeng Eurasia, Lempeng Pasifik, Lempeng Indo-Australia dan lempeng mikro yaitu Lempeng Philipina. Disamping itu Sulawesi Utara juga dilalui oleh sejumlah patahan yang suatu saat dapat menimbulkan gempabumi sehingga kondisi seperti ini harus diwaspadai.
Patahan-patahan tersebut menurut Efendi dan Bawono (1997) adalah Patahan Gorontalo, Patahan Amurang, Patahan Bolaang Mongondow dan Patahan Manado.

Peta geologi Sulawesi Utara menunjukan terdapat Patahan Manado yang melintasi kota Manado. Patahan Manado diidentifikasi dengan menggunakan metode geolistrik tahanan jenis konfigurasi WennerSchlumberger dan konfigurasi Dipole-dipole. Keunggulan konfigurasi ini adalah mendeteksi perlapisan batuan secara lateral 
dengan kedalaman 80 meter dibawah permukaan bumi. Metode geolistrik tahanan jenis dalam kondisi ini efektif dilakukan karena ketersediaan peralatan yang mudah untuk dimobilisasi dengan sistem pengoprasian alat yang tidak rumit.

Konfigurasi Wenner-Schlumberger dan Dipole-dipole ini nantinya dapat memberikan data tentang nilai tahanan jenis batuan dan kondisi struktur bagian bawah permukaan di daerah penelitan sehingga dapat dimanfaatkan mengidentifikas keberadaan patahan Manado.

\section{Sebaran Arus Listrik (Simetris Bola)}

Arus listrik yang dapat menembus permukaan bola yang luasnya A, tebalnya $d r$, dan beda potensial $d V$ antara dua titik dalam bola bagian luar dan dalam adalah :

$$
I=-\frac{A}{\rho} \frac{d V}{d r}
$$

Luas permukaan setengah bola $A=\frac{4 \pi r^{2}}{2}$, maka persamaan (1) menjadi :

$$
I=-\frac{2 \pi r^{2}}{\rho} \frac{d V}{d r}
$$

Tanda negatif menunjukan bahwa arus mengalir dari tempat berpotensial tinggi ke rendah.

\section{Potensial pada Dua Elektroda Arus Permukaan}

Dua elektroda arus yang dipasang dengan jarak tertentu seperti pada Gambar 1 . akan menyebabkan potensial pada titik-titik dekat permukaan dipengaruhi oleh kedua elektroda arus tersebut (Reynolds, 1997 dalam Bahri, 2005).

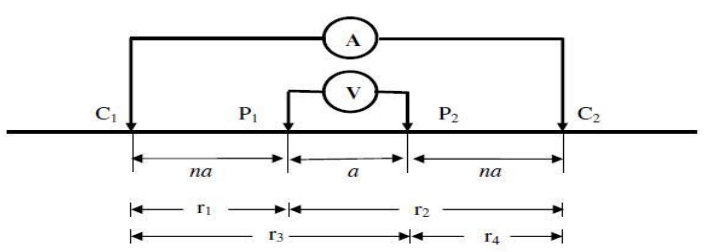

Gambar 1 Dua elektroda arus dan dua elektroda potensial pada permukaan homogen isotropis dengan tahanan jenis $\rho$ (Bahri, 2005).
Beda potensial antara P1 dan P2 dapat ditulis sebagai berikut :

$$
\begin{aligned}
& \left.\Delta V=\frac{I \rho}{2 \pi}\left\{\left(\frac{1}{r_{1}}-\frac{1}{r_{2}}\right)-\left(\frac{1}{r_{3}}-\frac{1}{r_{4}}\right)\right\} \ldots \ldots \ldots . .3\right) \\
& \text { Jika , } k=2 \pi\left[\left(\frac{1}{r_{1}}-\frac{1}{r_{2}}\right)-\left(\frac{1}{r_{3}}-\frac{1}{r_{4}}\right)\right]^{-1}
\end{aligned}
$$

Maka persamaan (3) dapat ditulis menjadi

$\rho=k \frac{\Delta V}{I}$

Dengan $I$ arus dalam ampere, $\Delta V$ beda potensial dalam Volt, $\rho$ resistivitas (tahanan jenis) dalam ohm meter dan $k$ merupakan faktor geometri dari konfigurasi elektroda potensial dan elektoda arus dalam meter.

\section{Konfigurasi Wenner-Shclumberger}

Konfigurasi Wenner-Schlumberger adalah konfigurasi dengan sistem aturan spasi yang konstan dengan catatan faktor pembanding " $n$ " untuk konfigurasi ini adalah perbandingan jarak antara elektroda AM dengan jarak antara $\mathrm{MN}$ seperti pada Gambar 2. Jika jarak antara elektroda potensial MN adalah a maka jarak antar elektroda arus (A dan B) adalah 2na+ a.

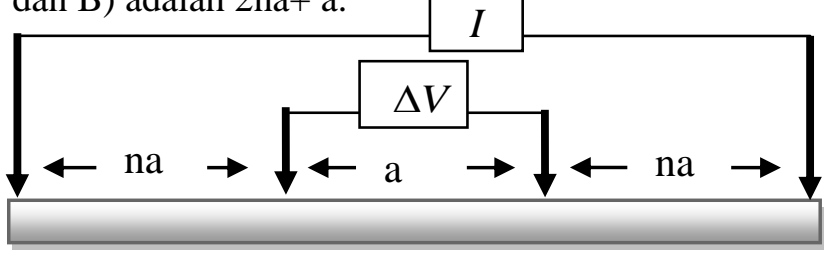

A M $\mathrm{N}$

Gambar 2 Pengaturan Elektroda Konfigurasi Wenner - Schlumberger

Faktor geometri dari konfigurasi Wenner-Sclumberger adalah :

$k=n(n+1) \pi a$

Dengan $a$ adalah jarak antara elektroda M dan N.

\section{Konfigurasi Dipole-dipole}

Metode pengukuran resistivitas pada konfigurasi Dipole-dipole, dilakukan dengan kedua elektroda arus dan elektroda potensial terpisah dengan jarak a. Elektroda arus dan elektroda potensial pada bagian dalam sistem konfigurasi terpisah sejauh na, dengan $\mathrm{n}$ adalah bilangan bulat. 
Skema posisi elektroda pada konfigurasi dipole-dipole dapat dilihat pada Gambar 3. Faktor geometri pada konfigurasi Dipole-dipole $\left(k_{d d}\right)$ adalah :

$$
k_{d d}=\operatorname{\pi an}(1+n)(2+n)
$$



Gambar 3 Konfigurasi Dipole-dipole

\section{METODE PENELITIAN \\ Desain Survei}

Desain survei pada Gambar 4 menggunakan lintasan 1, lintasan 2, lintasan 3, dan lintasan 4 secara berurutan diberi nama LJ1 (Lintasan Jalur 1), LJ2 (Lintasan Jalur 2), LJ3 (LintasanJalur 3), dan LJ4 (Lintasan Jalur 4). Pengambilan data dilakukan pada setiap lintasan dengan panjang lintasan 480 meter. Satu lintasan terdapat 48 titik pengukuran, dengan jarak masing- masing titik 10 meter, yang berlaku untuk semua lintasan.



Gambar 4 (a) Desain survei penelitian (b) Spasi antar elektroda satu dengan yang lain

Alat yang digunakan dalam pengambilan data adalah 1 unit multichannel and multielectrode resistivity and IP meter 46 simultaneous channel merek MAE X612EM, 1 unit GPS dan menggunakan konfigurasi Wenner- Schlumberger dan konfigurasi Dipole- dipole.

\section{Lokasi dan waktu}

Lokasi penelitian pada jalur patahan Manado di Jalan Ringroad, Kelurahan Malendeng, Kecamatan Paal II, kota Manado. Waktu pelaksanaan dari bulan Februari sampai bulan Juli 2015. Pengolahan data dilaksanakan di Laboratorium Geofisika Jurusan Fisika FMIPA UNSRAT dengan menggunakan bantuan perangkat lunak RES2DINV.

\section{HASIL DAN PEMBAHASAN \\ Metode Geolistrik Resistivitas Konfigurasi Wenner-Schlumberger}

\section{Lintasan LJ1}

Gambar 5 menunjukkan bahwa tidak ditemukan terobosan-terobosan bidang lemah dengan harga resistivitas yang rendah terhadap perlapisan antar batuan yang memiliki harga resistivitas yang lebih tinggi. Kedalaman hasil pencitraan resitivitas pada lintasan LJ1 adalah sampai pada kedalaman 78,8 meter dan tidak ditemukan adanya indikasi rekahan atau patahan.

\section{Lintasan LJ2}

Gambar 6 menunjukkan bahwa beberapa bidang lemah yang ditunjukan citra warna biru mempunyai nilai resistivitas berkisar antara $(8,55-15,2) \Omega m$. Bidang lemah tersebut dapat dilihat pada meter ke (180230) dari elektroda 1 dengan kedalaman berkisar (2,50-40) meter dari permukaan tanah yang memotong perlapisan antara batuan yang memiliki nilai resistivitas lebih tinggi, hasil penampang tersebut diperkirakan sebagai rekahan.

\section{Lintasan LJ3}

Gambar 7 menunjukkan bahwa beberapa bidang lemah dengan citra warna biru yang memiliki nilai resistivitas kecil berkisar antara (2,19- 6.91) $\Omega \mathrm{m}$ pada meter ke (170-210) dari elektroda 1 dengan kedalaman sekitar (15-40) meter dari permukaan tanah. Bidang lemah ini diduga sebagai kantong air yang diperkirakan berasal dari curah air hujan yang tertampung. Citra warna biru muda meter ke (320-400) pada permukaan diinterpretasikan sebagai rembesan air. Gambar tampang lintang pada lintasan LJ3 tidak ditemukan adanya indikasi keberadaan patahan. 


\section{Lintasan LJ4}

Gambar 8 menunjukkan bahwa beberapa bidang lemah yang ditunjukan dengan citra warna biru dan biru muda yang memiliki nilai resitivitas $4,84 \Omega \mathrm{m}$. Bidangbidang lemah dengan citra warna hijau $(15,3$ $\Omega m)$ dan kuning $(48,4 \Omega m)$ pada permukaan mulai dijumpai pada kedalaman dangkal, berturut- turut pada meter ke (30-60) dari elektroda 1 dengan kedalaman sekitar (2,5032) meter dari permukaan tanah, meter (190230) dengan kedalaman sekitar (2,50-40) meter dari permukaan tanah memotong perlapisan antara batuan yang memiliki nilai resistivitas lebih tinggi. Hasil penampang tersebut diinterpretasi sebagai rekahan.

\section{Metode Geolistrik Resistivitas Konfigurasi Dipole-dipole}

\section{Lintasan LJ1}

Gambar 9 menunjukkan bahwa hasil pengukuran mempunyai nilai resistivitas berkisar dari $0.00 \Omega m$ sampai $700 \Omega m$ dengan kedalaman hasil pencitraan resitivitas pada lintasan LJ1 sampai 78.8 meter. Citra warna biru yang ditunjukkan pada Gambar 9 dengan nilai resistivitas (100-200) $\Omega m$ diinterpretasi sebagai lempung pasiran. Pada lintasan ini tidak ditemukan adanya tandatanda rekahan atau patahan.

\section{Lintasan LJ2}

Gambar 10 menunjukkan bahwa tidak ditemukan terobosan- terobosan bidang lemah dengan harga resistivitas yang rendah terhadap perlapisan antar batuan yang memiliki harga resistivitas yang lebih tinggi dari batuan sekitarnya. Citra warna biru yang terlihat pada Gambar 10 dengan nilai resistivitas (100-200) $\Omega m$ diinterpretasi sebagai lempung pasiran disekitar lokasi pengukuran, dan tidak ditemukan adanya indikasi rekahan atau patahan.

\section{Lintasan LJ3}

Gambar 11 menunjukkan bahwa beberapa bidang lemah pada permukaan dengan kedalaman dangkal sekitar 12.8 meter (citra warna biru dan hijau) dari permukaan tanah. Bidang- bidang lemah yang memiliki citra warna biru dengan nilai resistivitas batuan yang berkisar antara (6,98-116) diduga adalah air yang berasal dari hujan sepanjang meter ke (120-480) dari elektroda 1. Pada lintasan ii tidak ditemukan adanya indikasi rekahan atau patahan.

\section{Lintasan LJ4}

Gambar 12 menunjukkan bahwa beberapa bidang lemah (citra warna biru dan hijau) yang memiliki nilai resistivitas berkisar antara $(6,01-160,01) \Omega \mathrm{m}$. Berturutturut pada meter ke (110-150) dari elektroda 1 dengan kedalaman sekitar (2,50-25) meter dari permukaan tanah, pada meter (150-220) dengan kedalaman sekitar (2,50-19) meter dari permukaan tanah, pada meter (330$360)$ dengan kedalaman sekitar (2,50-32) meter dari permukaan tanah. Bidang lemah tersebut diinterpretasi sebagai rekahan.

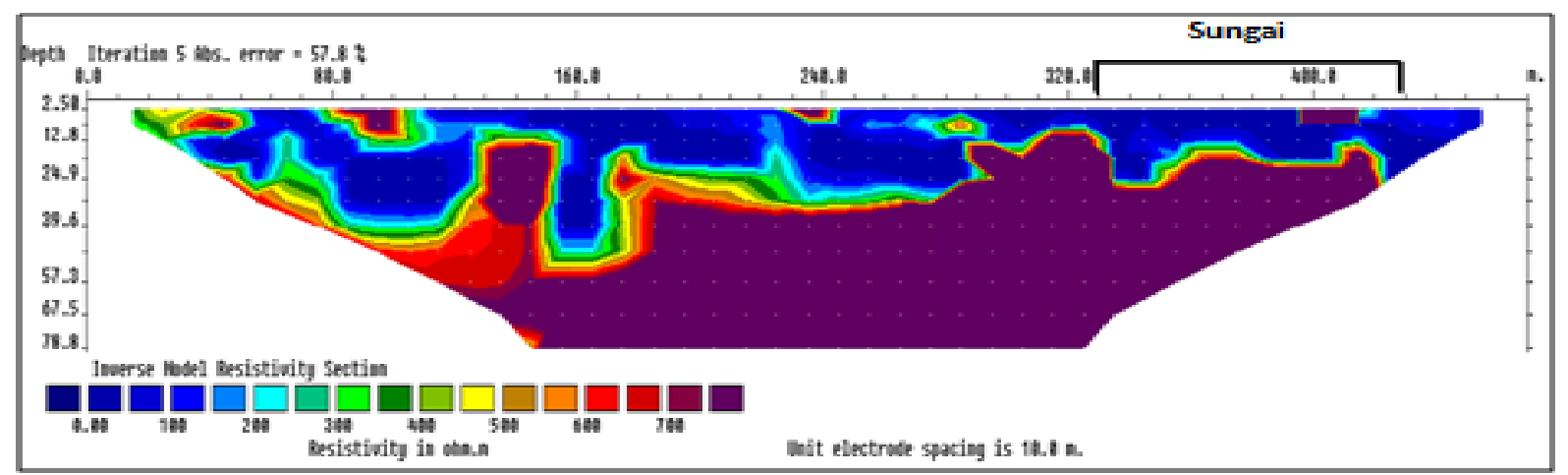

Gambar 5 Hasil pengolahan RES2DINVkonfigurasi Wenner- Schlumberger pada LJ1 


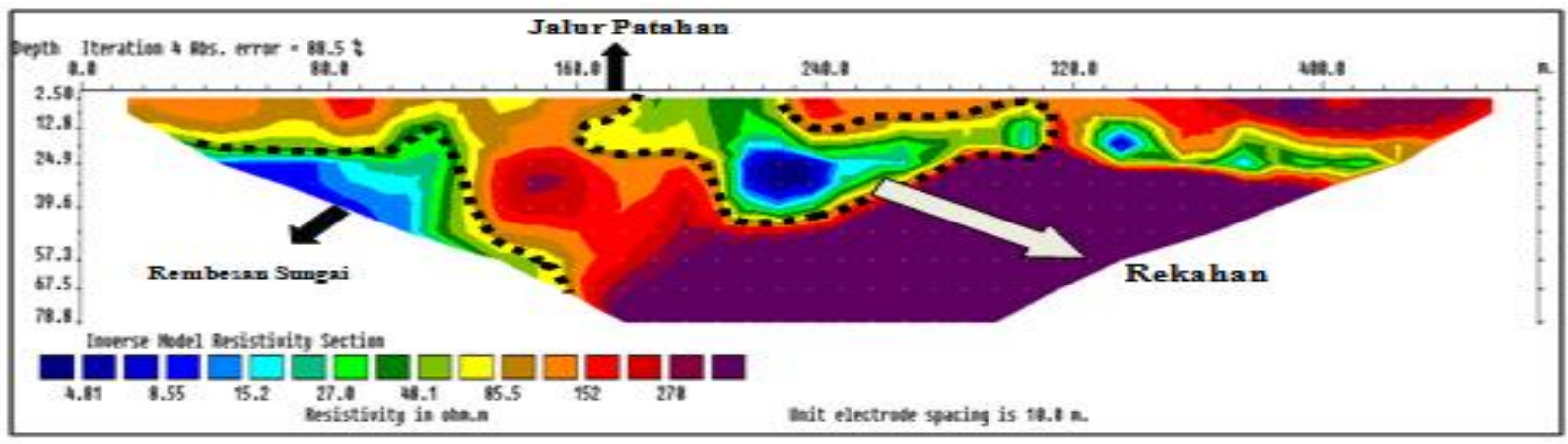

Gambar 6 Hasil pengolahan RES2DINV konfigurasi Wenner- Schlumberger pada LJ2

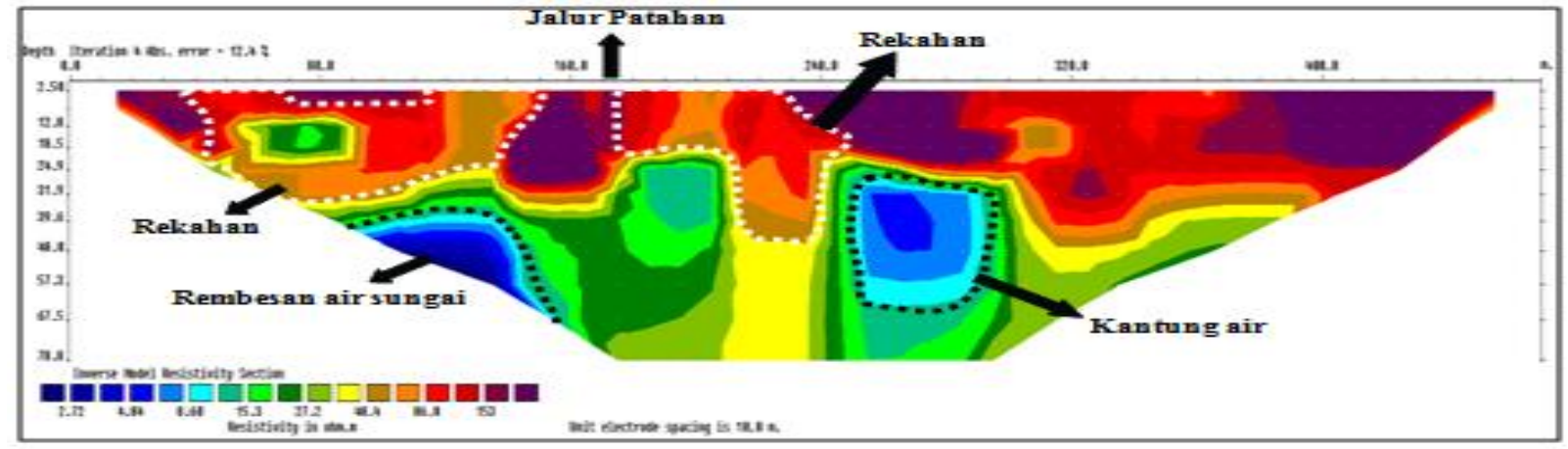

Gambar 7 Hasil pengolahan RES2DINV konfigurasi Wenner- Schlumberger pada LJ3

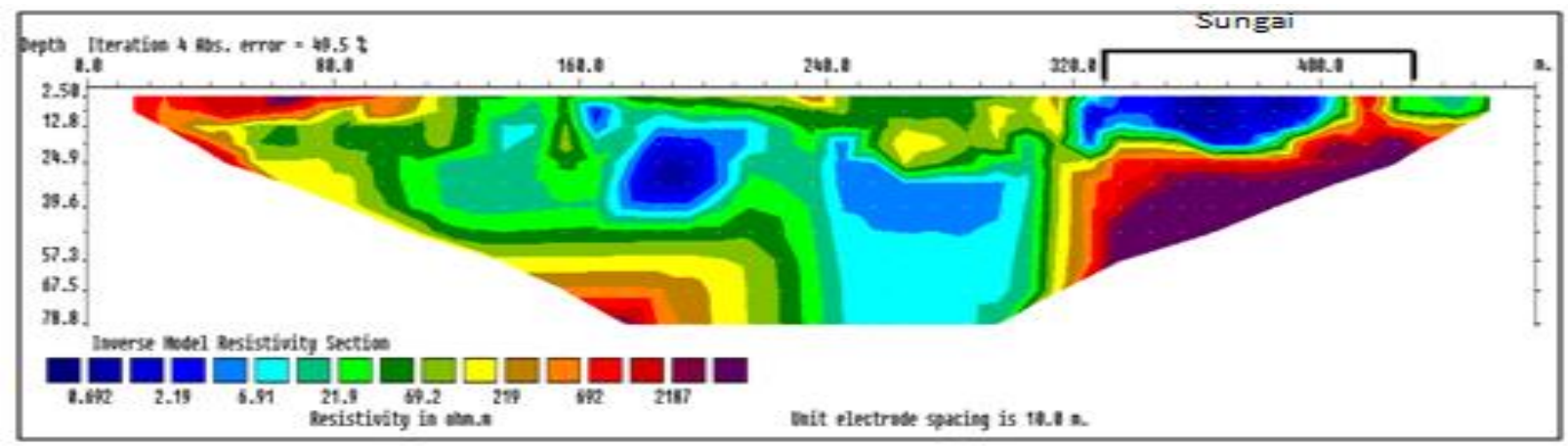

Gambar 8 Hasil pengolahaRES2DINV konfigurasi Wenner- Schlumberger pada LJ4

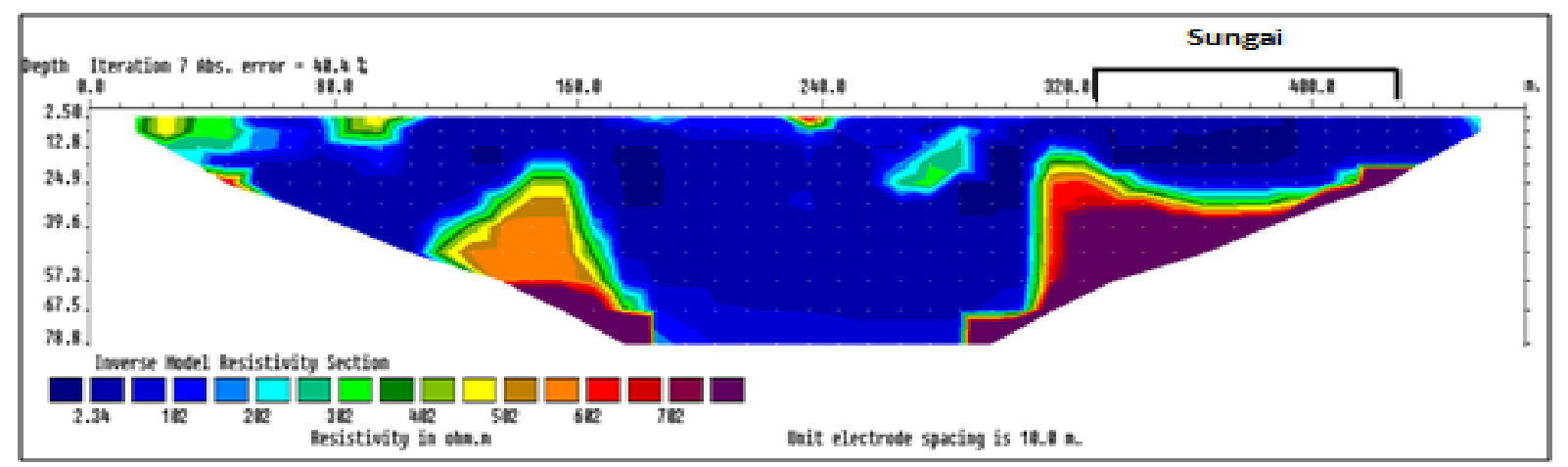

Gambar 9 Hasil pengolahan RES2DINV konfigurasi Dipole-dipole pada LJ1 


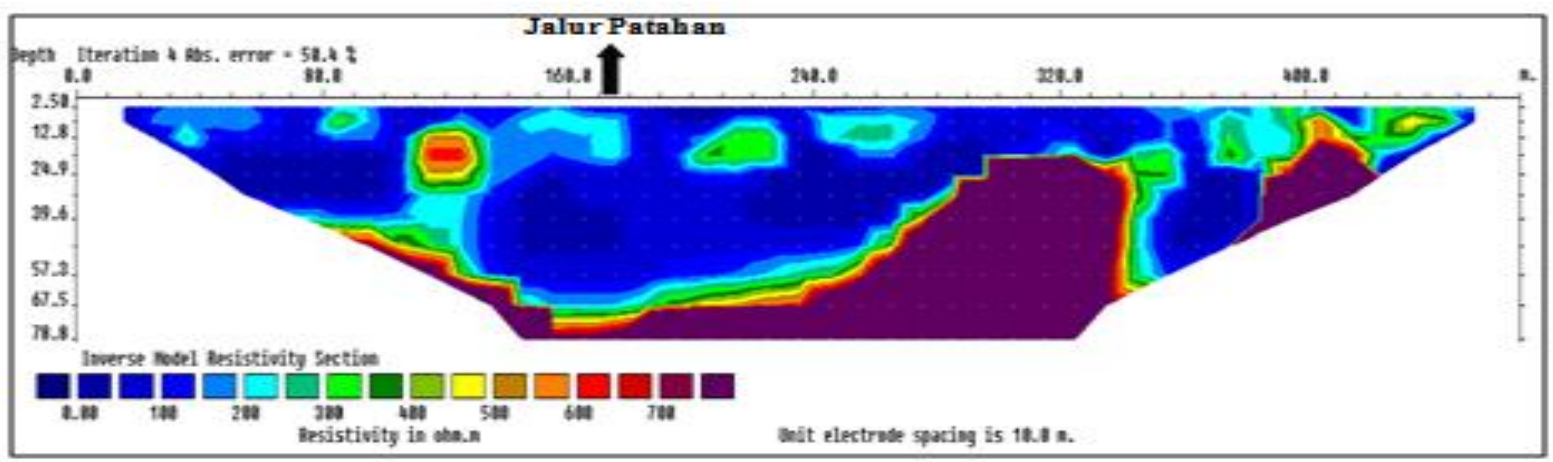

Gambar 10 Hasil pengolahan RES2DINV konfigurasi Dipole-dipole pada LJ2

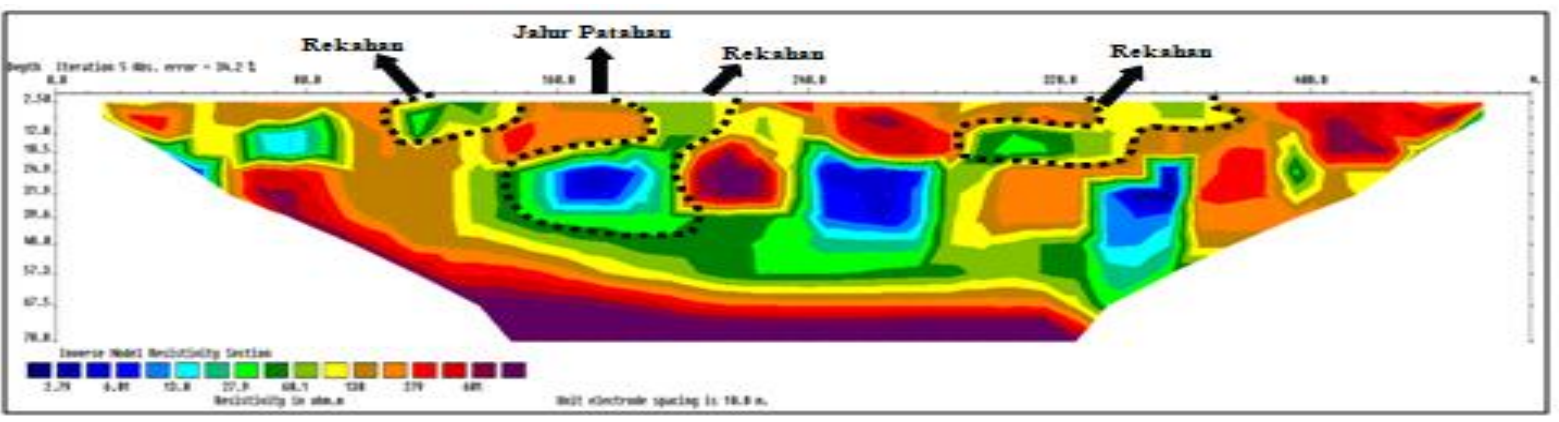

Gambar 11 Hasil pengolahan RES2DINV konfigurasi Dipole-dipole pada LJ3

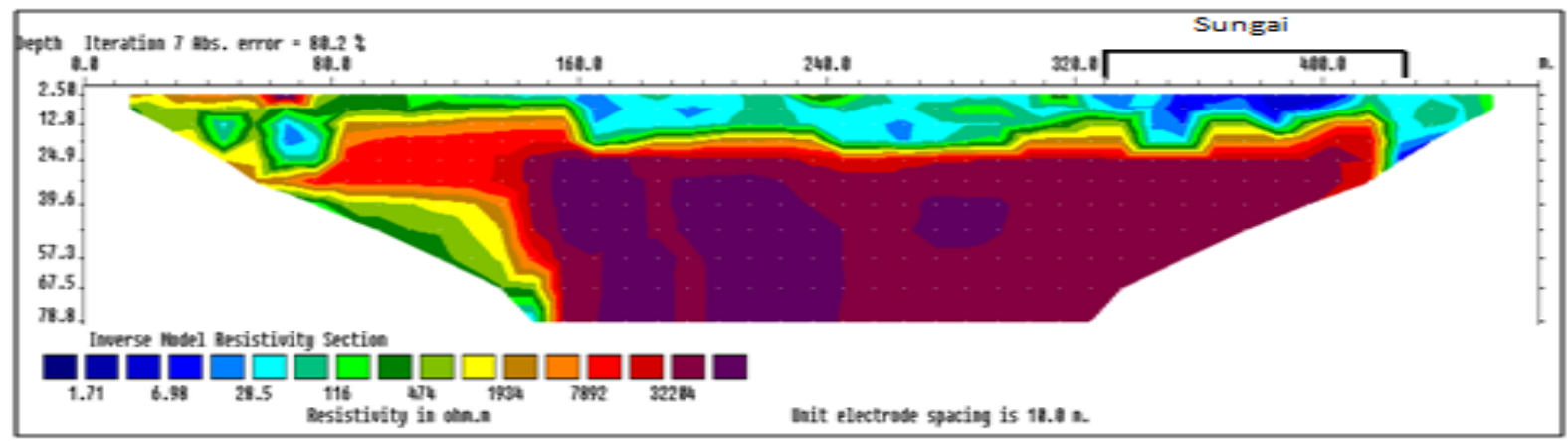

Gambar 12 Hasil pengolahan RES2DINV konfigurasi Dipole-dipole pada LJ4

\section{Analisis Jalur Patahan Manado Pada Lokasi Pengukuran}

Berdasarkan hasil pengolahan data dari keempat lintasan konfigurasi WennerSchlumberger dan konfigurasi Dipole-dipole menggunakan perangkat lunak RES2DINV diperoleh tampang lintang restivitas pada setiap lintasan. Hasil penampang yang dapat diamati dari lintasan LJ1 dan lintasan LJ3 adalah sesuai analisis citra warna bawah permukaan yang diperoleh dari pengukuran tidak memberikan informasi tentang keberadaan patahan. Oleh karena itu lintasan LJ1 dan lintasan LJ3 tidak dilalui oleh patahan.
Pendugaan patahan terdapat pada lintasan LJ2 dan lintasan LJ4 yang teramati dengan jelas menggunakan konfigurasi Wenner-Schlumberger. Konfigurasi Dipoledipole untuk lintasan LJ2 dari hasil penampang tidak ditemukan adanya patahan, sementara lintasan LJ4 konfigurasi Dipoledipole dapat memberikan informasi tentang keberadaan patahan.

\section{KESIMPULAN}

1. Identifikasi Patahan Manado dengan menggunakan metode geolistrik tahanan jenis konfigurasi Wenner- Schlumberger dan Dipole-dipole di jalan Ringroad 
Kelurahan Malendeng, menunjukan adanya bidang-bidang lemah pada lintasan 2 dan lintasan 4 yang memotong perlapisan antara batuan yang memiliki nilai resitivitas batuan berkisar antara (2.72-86) $\Omega m$ yang diperkirakan sebagai rekahan sampai kedalaman (2,50-40) meter dari permukaan tanah.

2. Identifikasi patahan manado dengan menggunakan metode geolistrik tahanan jenis konfigurasi Wenner-Schlumberger dapat memberikan gambaran yang lebih jelas tentang keberadaan rekahan dibandingkan dengan konfigurasi Dipoledipole.

\section{DAFTAR PUSTAKA}

Abidin, H. Z., Andreas, H., Meilano, I., Gamal, M.,Gumilar, Abdullah, C.I, 2009. Deformasi Koseismik dan Pascaseismik Gempa Yogyakarta 2006 dari Hasil Survei GPS.Jurnal Geologi Indonesia Vol. 4 (No. 4) : 275-284

Bahri. 2005. Hand Out Mata Kuliah Geofisika Lingkungan dengan Topik Metode Geolistrik Resistivitas. FMIPA ITS, Surabaya.

Effendi,A.C., dan S.S. Bawono. 1997. Peta Geologi Lembar Manado,Sulawesi utara,Edisi ke-2 pusat penelitian dan pengembangan Geologi,Bandung.

Andriani, Satuti., Romelan, A.H., Sutarno, 2010. Metode Geolistrik Imaging Konfigurasi Dipole-dipole Digunakan untuk Penelusuran Sistem Sungai Bawah Tanah Pada Kawasan Karst di Pacitan, Jawa Timur. Jurnal EKOSAINS/ Vol. II/ No.1/ Maret 2010. 